\title{
Rewritable Optical Patterns in Light-Responsive Ultrahigh Molecular Weight Polyethylene
}

\author{
Sarah S. D. Lafleur, ${ }^{\dagger}$ John R. Severn, ${ }^{\dagger}$ Rob C. P. Verpaalen, ${ }^{\dagger}$ A Albert P. H. J. Schenning, ${ }^{\dagger}$ \\ and Cees W. M. Bastiaansen ${ }^{*}, \dagger, \S_{\infty}$
}

\author{
${ }^{\dagger}$ Laboratory of Stimuli-responsive Functional Materials and Devices, Eindhoven University of Technology, P.O. Box 513, Eindhoven \\ $5600 \mathrm{MB}$, The Netherlands \\ ${ }^{\ddagger}$ DSM Material Science Center, Urmonderbaan 22, 6167RD Geleen, The Netherlands \\ ${ }^{\S}$ School of Engineering and Materials Science, Queen Mary, University of London, London E1 4NS, U.K.
}

\section{Supporting Information}

\begin{abstract}
Spiropyran is used as a photochromic dye to create colored patterns in highly drawn ultrahigh molecular weight polyethylene (UHMW PE) films. The dye is incorporated in highly crystalline, drawn UHMW PE tapes and fibers and isomerizes to its merocyanine state upon UV light irradiation, resulting in a color change from transparent to purple. The isomerization from merocyanine to spiropyran to erase the color can be simply induced by using heat or a green LED light. The combination of the use of a mask and the reversibility of the isomerization results in colored patterns that can be written, erased, and rewritten using UV light and heat or green LED light.

KEYWORDS: polymer fibers, light-responsive materials, photochromism, rewritable optical materials, spiropyran, ultrahigh molecular weight polyethylene
\end{abstract}

\section{INTRODUCTION}

Highly oriented and chain-extended ultrahigh molecular weight polyethylene (UHMW PE) has exceptional mechanical properties. For example UHMW PE fibers reach a maximum Young's modulus of $100-180 \mathrm{GPa}$ and a maximum tensile strength of 3-5 GPa. ${ }^{1-4}$ Thanks to these outstanding properties, these fibers are generally employed in very demanding applications, such as bulletproof vests, marine ropes, and cut resistant gloves. The mechanical properties of UHMW PE fibers are essentially the result of an extremely high degree of orientation and chain extension of UHMW PE polymer chains combined with a crystallinity above $90 \%$. To realize such a morphology, the fibers are extended ("drawn") to a very large deformation (so-called draw ratio) at elevated temperatures in the solid state.

Stimuli-responsive polymers that respond to an external stimulus, such as light or heat, by changing their properties are one of the focal points in materials science. Currently, there is an increased interest in making existing polymers responsive for high-end applications. Despite its remarkable mechanical properties, UHMW PE has not been used to fabricate stimuliresponsive materials as the highly crystalline matrix is believed to restrict motion of embedded, small responsive molecules. ${ }^{5-7}$ However, if light could be used as a stimulus to develop mechanically robust UHMW PE-based photoresponsive materials, such materials could lead to new applications in the field of optical storage, ${ }^{8,9}$ sensors, ${ }^{10-14}$ actuators, artificial muscle, and soft-robotics. The few examples of light-responsive polyethylene that exist in literature do not use UHMW PE, but low density polyethylene (LDPE) matrixes to create actuators $^{15-17}$ and photopatterns. ${ }^{18}$

In the past, photochromic dyes such as azobenzene, spirooxazine, and spiropyran (SP) molecules have attracted a lot of interest for the construction of light-responsive materials. ${ }^{19,20}$ These organic photochromic dyes undergo an isomerization reaction in response to ultraviolet (UV) or visible light. ${ }^{21}$ In the case of SP, reversible isomerization upon light exposure provides the feature to switch between different functional properties, such as color and polarity. When irradiated with UV light, heterolytic $\mathrm{C}_{\text {spiro }}-\mathrm{O}$ bond cleavage of the SP occurs and merocyanine (MC) is formed (Figure 1). ${ }^{19}$ The SP is colorless and apolar having a dipole moment in the range 4-6 D, while the MC form has a deep blue/purple color being more apolar with a dipole moment of 14-18 D. ${ }^{19}$ By incorporating spiropyran in nonstretched polymers, studies showed the possibility to photocontrol the polymer fluorescence, ${ }^{22-24}$ solubility, ${ }^{25-27}$ transport through polymeric systems, ${ }^{28}$ mechanical properties, ${ }^{29}$ and metal ion complexation. $^{30,31}$ In the above-described materials, amorphous or semicrystalline polymers were employed with a low Young's modulus $(<3 \mathrm{GPa})$ and tensile strength $(<0.1 \mathrm{GPa}) .{ }^{32,33}$ Here, so-called gel cast ultradrawn UHMW PE is used with Young's moduli and tensile strengths above 100 and $3 \mathrm{GPa}$,

Received: November 12, 2018

Accepted: January 31, 2019

Published: January 31, 2019 


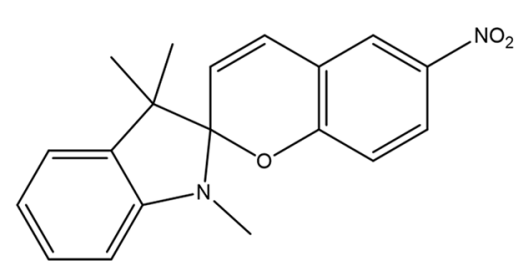

Spiropyran (SP), $\mu=4.3 \mathrm{D}$
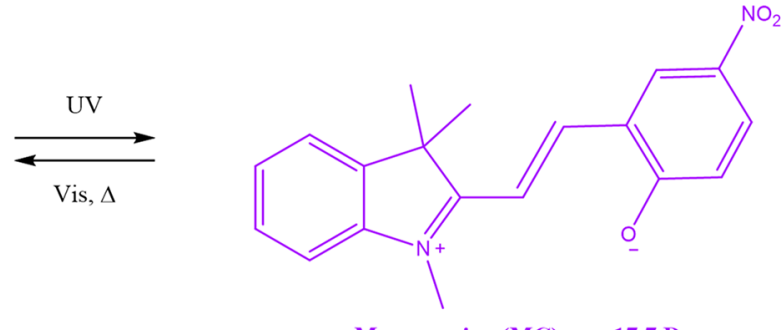

Merocyanine (MC), $\mu=17.7 \mathrm{D}$
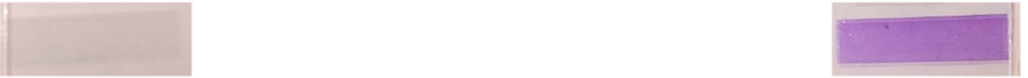

Figure 1. Photochromism of 1,3-dihydro-1,3,3-trimethyl-6-nitrospiro[2H-1-benzopyran-2,2-(2H)-indole] (SP). Upon exposure to UV, the purple merocyanine $(\mathrm{MC})$ is formed, while upon exposure to visible light and/or heat, the SP spiropyran is obtained again. Top: isomerization of SP and MC molecules. ${ }^{19}$ Bottom: photographs of drawn UHMW PE tapes containing SP before and after UV light irradiation.

respectively. SP dyes have never been incorporated in such polymers to create anisotropic light-responsive materials.

Here, a method to fabricate light-responsive UHMW PE tapes and fibers using spiropyran is presented. Spiropyran is incorporated in the UHMW PE tapes and fibers as a photochromic additive during gel casting or after placing the polymer in spiropyran solution. The polymer irradiated with UV light locally becomes purple and is used to make colored patterns.

\section{RESULTS AND DISCUSSION}

For the fabrication of the light-responsive UHMW PE tapes, 3 wt \% SP is incorporated in UHMW PE during gel casting. The SP and UHMW PE are dissolved in xylene at $135^{\circ} \mathrm{C}$. The solution is then cast in an aluminum tray and after evaporation of the solvent at room temperature (for several days), the UHMW PE films containing SP are obtained. Subsequently, samples are cut from the slightly yellow colored tape and are thereafter drawn on a hot plate to a draw ratio of 30 and 60 (UH_DR30 and UH_DR60). The stretched, anisotropic sample is transparent as the exposure to high temperatures promotes the formation of the transparent SP isomer (Figure 2). After irradiation with UV light $\left(80 \mathrm{~mJ} \mathrm{~cm}^{-2}\right)$, the drawn tape becomes purple and the UV-vis spectrum exhibits an absorption band centered at $550 \mathrm{~nm}$. The peak at $550 \mathrm{~nm}$ is characteristic for the merocyanine (MC) isomer and demonstrates the photoisomerization of the SP to the MC

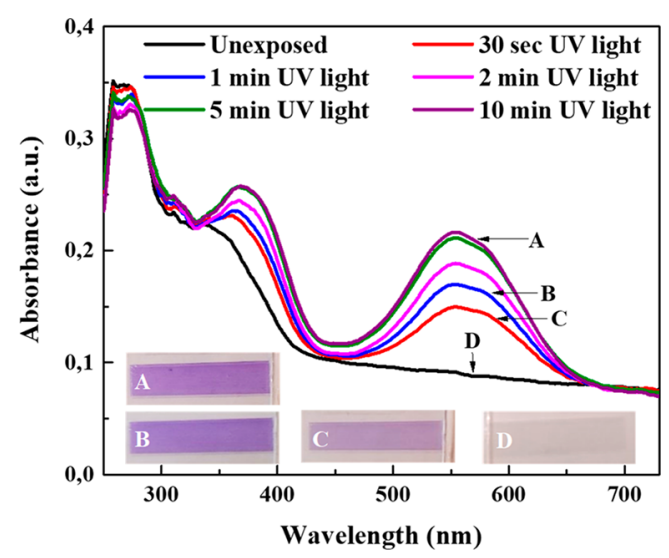

Figure 2. Isomerization from SP to MC in a UH DR60 by irradiation with UV light (with a dose of $80 \mathrm{~mJ} \mathrm{~cm}^{-2}$ ) and corresponding pictures of the UHMW PE tape $\left(0.3 \times 3 \mathrm{~cm}^{2}\right)$ becoming purple. isomer. The maximum conversion is obtained after $5 \mathrm{~min}$ of UV light irradiation (Figure 2). ${ }^{34}$

The reversibility of the isomerization is studied using heat and green light $(565 \mathrm{~nm})$. After an irradiation of 5 min with UV light, the UH_DR60 tape is heated to $70{ }^{\circ} \mathrm{C}$ and the decrease of its absorption at $550 \mathrm{~nm}$ is monitored (Figure 3 ). Heating for $2 \mathrm{~min}$ at $70{ }^{\circ} \mathrm{C}$ is enough to fully isomerize the MC back to SP. An exposure to green LED light for $30 \mathrm{~min}$ at room temperature is also sufficient to fully reverse the system to the SP state. Photoisomerization of the UH_DR60 tape was also examined by cycling repeatedly between the SP and MC isomers using either heat $\left(70{ }^{\circ} \mathrm{C}\right.$ ) or green light (see Figure $\mathrm{S} 1$ ), revealing that this rewritable process can only be used a couple of times. Such a behavior is typical for nitro-spiropyran derivatives. $^{35}$

The effect of the draw ratio on the isomerization from SP to $\mathrm{MC}$ is also studied (Figure 4a,b). The absorption at $550 \mathrm{~nm}$ of UH_DR30 after $5 \mathrm{~min}$ of UV light irradiation seems to be almost double the absorption for UH_DR60. However, when the absorption is corrected for the tape thickness by calculating it per $10 \mu \mathrm{m}$ film thickness, both UH_DR30 and UH_DR60 display similar absorption and isomerization characteristics. Therefore, the draw ratio, thus Young's modulus of the matrix, does not have a negative impact on the isomerization kinetics. The coloration kinetics of the SP to MC isomerization can be described (Figure 4B) using a first-order exponential fit, having rate constants on the order of $\sim-0.015 \mathrm{~s}^{-1} .{ }^{36,37}$ These values are comparable to rate constants found in poly(methyl methacrylate) matrixes. ${ }^{38}$ In addition, decoloration kinetics in response to green light $(\lambda=565 \mathrm{~nm})$ or heat $\left(70{ }^{\circ} \mathrm{C}\right)$ can also be fitted using a first order exponential fit, revealing a faster thermal decoloration reaction (Figures S2a,b and S3).

With the ability of spiropyran to isomerize and change color, an easy method exists to pattern UHMW PE containing this dye. An image can be created within minutes by using a mask between the oriented UHMW PE material and the UV lamp, as shown in Figure 5. Various patterns can be generated, from image patterns to logos, with a high contrast. Moreover, using heat makes it possible to write, erase, rewrite, and erase again different patterns on the same tape.

The photopatterning method can also be used on UHMW PE fibers as shown in Figure 6. The incorporation of spiropyran into the UHMW PE fibers can be performed directly by diffusing the dye into the fiber. First, a solution was prepared by dissolving SP in xylene at room temperature. Then, the UHMW PE fibers were placed in an aluminum tray containing the SP solution. The xylene slowly evaporated and 

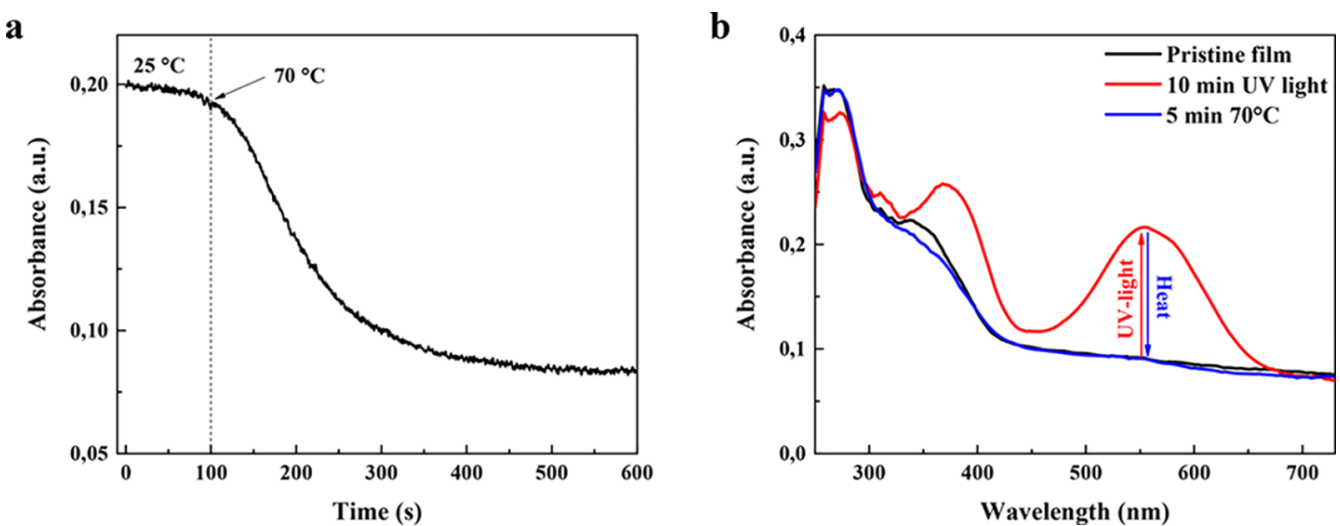

Figure 3. (a) Isomerization from MC to SP using heat of UH_DR60. Absorbance at $550 \mathrm{~nm}$ of the film after an increase of the temperature from 25 to $70^{\circ} \mathrm{C}$. (b) UV-vis spectra of the film showing the reversibility of the patterning during the first cycle using heat.
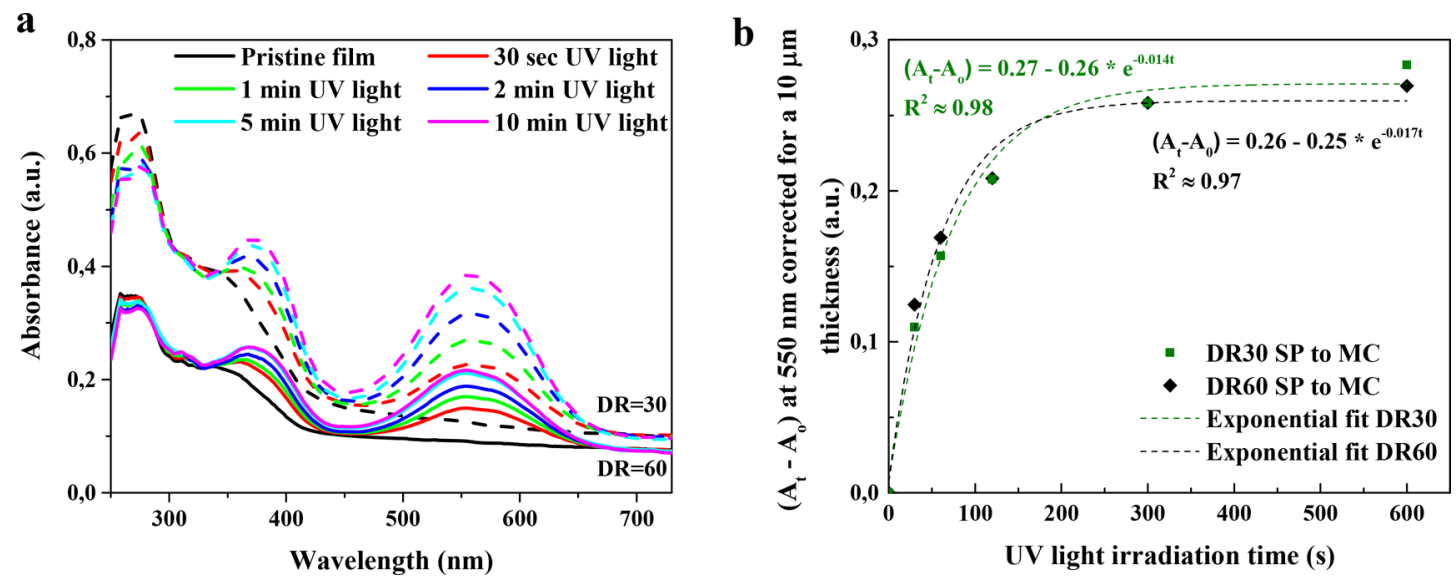

Figure 4. (a) UV-vis spectra of the films showing the isomerization from SP to MC upon UV irradiation for DR = 30 (dotted lines) and 60 (full lines). (b) SP to MC coloration process fitted using first-order exponential function in a $\left(A_{t}-A_{0}\right)$ versus time plot at $\lambda_{\max }=550 \mathrm{~nm}$.

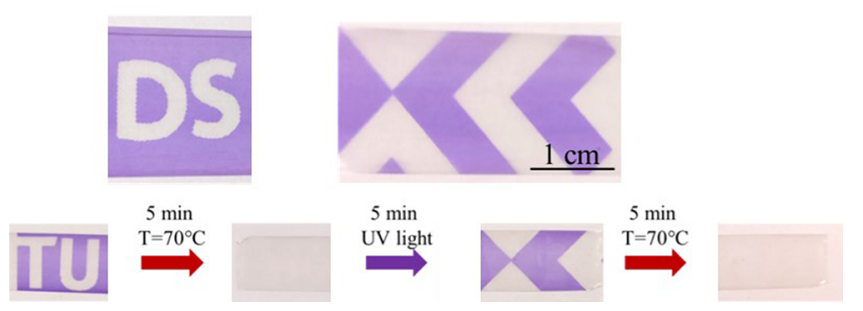

Figure 5. Patterns and images photopatterned into oriented UHMW PE films containing SP drawn 30 times and a demonstration of the reversibility of the patterns using heat.

after a day the fibers were dry. After the evaporation of the solvent, the fibers containing SP were collected and photopatterned. The fibers were then irradiated with UV light in combination with a mask following the same method as for the UHMW PE tapes. The photopatterning is also shown to be reversible in the case of the fibers. After 2 days at room temperature, the fibers do not show a pattern anymore and became white again. Ultradrawn, UHMW PE films and fibers are sensitive to counterfeiting, and the above recording and fading can potentially be used for advanced anticounterfeiting features. $10,11,39$

\section{CONCLUSIONS}

The new facile method presented here opens the possibility to fabricate light-responsive solid state drawn UHMW PE tapes

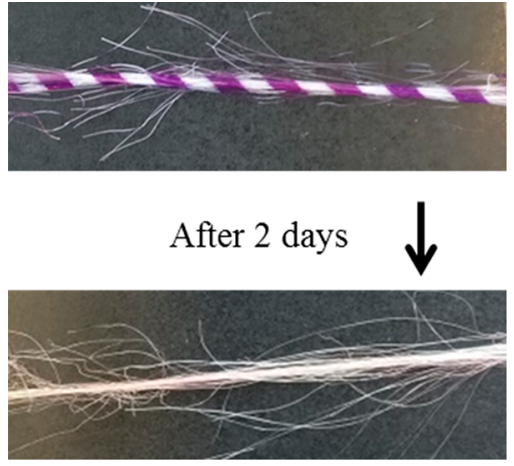

Figure 6. Photopatterning of UHMW PE fibers. The fibers are first irradiated with UV light for 5 min using a mask. After 2 days at room temperature, the dye isomerizes back from MC to SP, which results in the pattern disappearing and the fibers becoming white again.

and fibers. Highly crystalline, mechanically robust UHMW PE polymers were embedded with a SP photochromic dye to exploit its erasable and rewritable functional properties as being exposed to UV light, heat, and green light. UV light in combination with a mask can be used to fabricate the colored pattern while heat or green light can be used to erase it. This photopatterning method can simply be extended to other polymers. The reversibility of the spiropyran can most likely be increased by using more stable photochromic dyes. ${ }^{40}$ The switch between isomers could be further used to change more 
properties such as polarity, which can lead to new applications. The incorporation of spiropyran can also be performed directly on the finished end products such as fibers. This can be an industrial advantage as it means that no changes are required in the processing of the fibers. Optically responsive UHMW PE fibers are interesting as they are used in a broad range of application where design is important such as clothing.

\section{EXPERIMENTAL SECTION}

Materials. Ultrahigh molecular weight $\mathrm{PE}$ was obtained from DSM with a number-average molecular weight $M_{\mathrm{n}}$ of $310 \mathrm{~kg} / \mathrm{mol}$ and a weight-average molecular weight $M_{\mathrm{w}}$ of $3300 \mathrm{~kg} / \mathrm{mol}$. UHMW PE fibers were kindly provided by DSM. 1,3-Dihydro-1,3,3-trimethyl-6nitrospiro[2H-1-benzopyran-2,2-(2H)-indole] (SP) was purchased from Acros Organics. All reagents were used as received without further purification.

Preparation of Stretched UHMW PE Tapes. Oriented PE films containing spiropyran were produced according to the following procedure. First, the UHMW PE powder was suspended in xylene at room temperature at concentration of 1.5 wt \% with 0.05 wt $\%$ of antioxidant Irganox 1010 and with 3 wt \% of SP added. Air trapped by the powder particles was removed by the application of a vacuum. Then the flask containing the suspension was heated under continuous stirring at $130{ }^{\circ} \mathrm{C}$ in an oil bath. Once the Weissenberg effect was observed, the stirring was stopped and the flask was kept in the oil bath for $1 \mathrm{~h}$. The solution was then cast in an aluminum tray at room temperature. Upon cooling, the solution turned opaque and became gel like. Finally, xylene was evaporated for several days in a fume hood and films of uniform thickness were obtained. A piece of the film $(1 \times 3 \mathrm{~cm})$ was cut and stretched on a hot plate at $120^{\circ} \mathrm{C}$ using pliers. The draw ratio was determined by the displacement of two ink marks on the film.

Irradiation with UV Light and Green Light. The UHMW PE tapes containing SP were irradiated with UV and green light. For the UV light irradiation an Exfo lamp was used with a wavelength from 320 to $500 \mathrm{~nm}$ and a dose of $80 \mathrm{~mJ} . \mathrm{cm}^{-2}$. The green light to reverse the isomerization was generated with an LED with a wavelength of $565 \mathrm{~nm}$ and an intensity of roughly $15 \mathrm{~mJ} . \mathrm{cm}^{-2}$.

UV-Vis Spectroscopy. The chain-extended tapes were placed between two quartz slides with a drop of silicon oil. The absorption was measured in the range $250-730 \mathrm{~nm}$ on a Shimadzu UV-3102 PC spectrophotometer at a $1 \mathrm{~nm}$ interval.

\section{ASSOCIATED CONTENT}

\section{S Supporting Information}

The Supporting Information is available free of charge on the ACS Publications website at DOI: 10.1021/acsapm.8b00117.

Photoisomerization cycles, UV-vis spectra, decoloration kinetics, and solvent exposure of the ultradrawn UHMW PE tapes (PDF)

\section{AUTHOR INFORMATION}

\section{Corresponding Author}

*E-mail: c.w.m.bastiaansen@tue.nl.

\section{ORCID}

Rob C. P. Verpaalen: 0000-0001-6239-5114

Albert P. H. J. Schenning: 0000-0002-3485-1984

Cees W. M. Bastiaansen: 0000-0003-1198-7528

\section{Notes}

The authors declare no competing financial interest.

\section{ACKNOWLEDGMENTS}

This work was financially supported by DSM Dyneema BV, The Netherlands. The work of Rob C.P. Verpaalen forms part of the research programme of DPI, programme 731.015.502.

\section{REFERENCES}

(1) Smith, P.; Lemstra, P. J.; Pijpers, J. P. L.; Kiel, A. M. UltraDrawing of High Molecular Weight Polyethylene Cast from Solution III. Morphology and Structure. Colloid Polym. Sci. 1981, 259, 10701080.

(2) Lemstra, P. J.; van Aerle, N. A. J. M.; Bastiaansen, C. W. M. Chain-Extended Polyethylene. Polym. J. 1987, 19, 85-98.

(3) Yeh, J. T.; Chang, S. S. Ultradrawing Gel Films of Blends of Ultrahigh Molecular Weight Polyethylene and Low Molecular Weight Polyethylenes with Different Molecular Weights. J. Mater. Sci. 2000, $35,3227-3236$.

(4) Sawai, D.; Nagai, K.; Kubota, M.; Ohama, T.; Kanamoto, T. Maximum Tensile Properties of Oriented Polyethylene, Achieved by Uniaxial Drawing of Solution-Grown Crystal Mats: Effects of Molecular Weight and Molecular Weight Distribution. J. Polym. Sci., Part B: Polym. Phys. 2006, 44, 153-161.

(5) Ercole, F.; Davis, T. P.; Evans, R. A. Comprehensive Modulation of Naphthopyran Photochromism in a Rigid Host Matrix by Applying Polymer Conjugation. Macromolecules 2009, 42, 1500-1511.

(6) Sriprom, W.; Néel, M.; Gabbutt, C. D.; Heron, B. M.; Perrier, S. Tuning the Color Switching of Naphthopyrans via the Control of Polymeric Architectures. J. Mater. Chem. 2007, 17, 1885-1893.

(7) Micciche, F.; Ramakrishnan, V.; Hoeks, T. L. The Effect of Molecular Structure on the Secondary Transitions and Their Influence on the Decoloration Kinetics of Photochromic Dyes in Co-Polycarbonates. J. Polym. Sci., Part B: Polym. Phys. 2016, 54, $1593-1601$.

(8) Abdollahi, A.; Alinejad, Z.; Mahdavian, A. R. Facile and Fast Photosensing of Polarity by Stimuli-Responsive Materials Based on Spiropyran for Reusable Sensors: A Physico-Chemical Study on the Interactions. J. Mater. Chem. C 2017, 5, 6588-6600.

(9) Weis, P.; Wang, D.; Wu, S. Visible-Light-Responsive Azopolymers with Inhibited $\pi$ - $\pi$ Stacking Enable Fully Reversible Photopatterning. Macromolecules 2016, 49, 6368-6373.

(10) Abdollahi, A.; Sahandi-Zangabad, K.; Roghani-Mamaqani, H. Light-Induced Aggregation and Disaggregation of Stimuli-Responsive Latex Particles Depending on Spiropyran Concentration: Kinetics of Photochromism and Investigation of Reversible Photopatterning. Langmuir 2018, 34, 13910-13923.

(11) Abdollahi, A.; Sahandi-Zangabad, K.; Roghani-Mamaqani, H. Rewritable Anticounterfeiting Polymer Inks Based on Functionalized Stimuli-Responsive Latex Particles Containing Spiropyran Photoswitches: Reversible Photopatterning and Security Marking. ACS Appl. Mater. Interfaces 2018, 10, 39279-39292.

(12) Terpstra, A. S.; Hamad, W. Y.; Maclachlan, M. J. Photopatterning Freestanding Chiral Nematic Mesoporous Organosilica Films. Adv. Funct. Mater. 2017, 27, 1703346.

(13) Abdollahi, A.; Mahdavian, A. R.; Salehi-Mobarakeh, H. Preparation of Stimuli-Responsive Functionalized Latex Nanoparticles: The Effect of Spiropyran Concentration on Size and Photochromic Properties. Langmuir 2015, 31, 10672-10682.

(14) Abdollahi, A.; Rad, J. K.; Mahdavian, A. R. Stimuli-Responsive Cellulose Modified by Epoxy-Functionalized Polymer Nanoparticles with Photochromic and Solvatochromic Properties. Carbohydr. Polym. 2016, 150, 131-138.

(15) Uznanski, P.; Kryszewski, M. Bullelin. Polym. Bull. 1991, 26, 437-443.

(16) Bobrovsky, A.; Shibaev, V.; Elyashevitch, G.; Rosova, E.; Shimkin, A.; Shirinyan, V.; Bubnov, A.; Kaspar, M.; Hamplova, V.; Glogarova, M. New Photosensitive Polymer Composites Based on Oriented Porous Polyethylene Filled with Azobenzene-Containing LC Mixture: Reversible Photomodulation of Dichroism and Birefringence. Liq. Cryst. 2008, 35, 533-539. 
(17) Ryabchun, A.; Bobrovsky, A.; Stumpe, J.; Shibaev, V. Novel Generation of Liquid Crystalline Photo-Actuators Based on Stretched Porous Polyethylene Films. Macromol. Rapid Commun. 2012, 33, 991-997.

(18) Varghese, S.; Severn, J. R.; Schenning, A. P. H. J. Photoresponsive Polyolefins. In Photoactive Functional Soft Materials: Preparation, Properties, and Applications; Li, Q., Ed.; John Wiley \& Sons, 2019; pp 319-340.

(19) Klajn, R. Spiropyran-Based Dynamic Materials. Chem. Soc. Rev. 2014, 43, 148-184.

(20) Qiao, Q.; Zhang, X.; Lu, Z.; Wang, L.; Liu, Y.; Zhu, X.; Li, J. Formation of Holographic Fringes on Photochromic Ag/TiO2nanocomposite Films. Appl. Phys. Lett. 2009, 94, 074104.

(21) Fu, S.; Liu, Y.; Lu, Z.; Dong, L.; Hu, W.; Xie, M. Photo-Induced Birefringence and Polarization Holography in Polymer Films Containing Spirooxazine Compounds Pre-Irradiated by UV Light. Opt. Commun. 2004, 242, 115-122.

(22) Zhu, M. Q.; Zhu, L.; Han, J. J.; Wu, W.; Hurst, J. K.; Li, A. D. Q. Spiropyran-Based Photochromic Polymer Nanoparticles with Optically Switchable Luminescence. J. Am. Chem. Soc. 2006, 128, 4303-4309.

(23) Zhu, L.; Wu, W.; Zhu, M. Q.; Han, J. J.; Hurst, J. K.; Li, A. D. Q. Reversibly Photoswitchable Dual-Color Fluorescent Nanoparticles as New Tools for Live-Cell Imaging. J. Am. Chem. Soc. 2007, 129, 3524-3526.

(24) Li, C.; Zhang, Y.; Hu, J.; Cheng, J.; Liu, S. Reversible ThreeState Switching of Multicolor Fluorescence Emission by Multiple Stimuli Modulated FRET Processes within Thermoresponsive Polymeric Micelles. Angew. Chem., Int. Ed. 2010, 49, 5120-5124.

(25) Koňák, C.; Kopečková, P.; Kopeček, J. Photoregulated Association of N-(2-Hydroxypropyl)Methacrylamide Copolymers with Azobenzene-Containing Side Chains. Macromolecules 1992, 25, $5451-5456$

(26) Edahiro, J. I.; Sumaru, K.; Takagi, T.; Shinbo, T.; Kanamori, T. Photoresponse of an Aqueous Two-Phase System Composed of Photochromic Dextran. Langmuir 2006, 22, 5224-5226.

(27) Lee, H., Il; Wu, W.; Oh, J. K.; Mueller, L.; Sherwood, G.; Peteanu, L.; Kowalewski, T.; Matyjaszewski, K. Light-Induced Reversible Formation of Polymeric Micelles. Angew. Chem., Int. Ed. 2007, 46, 2453-2457.

(28) Sugiura, S.; Sumaru, K.; Ohi, K.; Hiroki, K.; Takagi, T.; Kanamori, T. Photoresponsive Polymer Gel Microvalves Controlled by Local Light Irradiation. Sens. Actuators, A 2007, 140, 176-184.

(29) Davis, D. A.; Hamilton, A.; Yang, J.; Cremar, L. D.; Van Gough, D.; Potisek, S. L.; Ong, M. T.; Braun, P. V.; Martínez, T. J.; White, S. R.; Moore, J. S.; Sottos, N. R. Force-Induced Activation of Covalent Bonds in Mechanoresponsive Polymeric Materials. Nature 2009, 459, $68-72$.

(30) Suzuki, T.; Kato, T.; Shinozaki, H. Photo-Reversible Pb 21 -Complexation of Thermosensitive Poly (N -Isopropyl AcrylamideCo -Spiropyran Acrylate) in Water. Chem. Commun. 2004, 2, 20362037.

(31) Fries, K. H.; Driskell, J. D.; Samanta, S.; Locklin, J. Spectroscopic Analysis of Metal Ion Binding in Spiropyran Containing Copolymer Thin Films. Anal. Chem. 2010, 82, 33063314.

(32) Dixit, M.; Mathur, V.; Gupta, S.; Baboo, M.; Sharma, K.; Saxena, N. S. Morphology, Miscibility and Mechanical Properties of PMMA/PC Blends. Phase Transitions 2009, 82, 866-878.

(33) Gilmour, I. W.; Trainor, A.; Haward, R. N. Elastic Moduli of Glassy Polymers at Low Strains. J. Appl. Polym. Sci. 1979, 23, 31293138.

(34) Ramos-Garcia, R.; Delgado-Macuil, R.; Iturbe-Castillo, D.; De Los Santos, E. G.; Corral, F. S. Polarization Dependence on the Holographic Recording in Spiropyran-Doped Polymers. Opt. Quantum Electron. 2003, 35, 641-650.

(35) Chen, J.; Wang, D.; Turshatov, A.; Muñoz-Espí, R.; Ziener, U.; Koynov, K.; Landfester, K. One-Pot Fabrication of Amphiphilic
Photoswitchable Thiophene-Based Fluorescent Polymer Dots. Polym. Chem. 2013, 4, 773-781.

(36) Abdollahi, A.; Mouraki, A.; Sharifian, M. H.; Mahdavian, A. R. Photochromic Properties of Stimuli-Responsive Cellulosic Papers Modified by Spiropyran-Acrylic Copolymer in Reusable PH-Sensors. Carbohydr. Polym. 2018, 200, 583-594.

(37) Lin, J. S. Interaction between Dispersed Photochromic Compound and Polymer Matrix. Eur. Polym. J. 2003, 39, 1693-1700.

(38) Pariani, G.; Bianco, A.; Castagna, R.; Bertarelli, C. Kinetics of Photochromic Conversion at the Solid State: Quantum Yield of Dithienylethene-Based Films. J. Phys. Chem. A 2011, 115, 1218412193.

(39) Zhang, T.; Fu, L.; Chen, Z.; Cui, Y.; Liu, X. Photochromic Properties of Spiropyran in Epoxy Resin as Anti-Counterfeiting Coating on Flexible Materials. Prog. Org. Coat. 2016, 100, 100-104.

(40) Ter Schiphorst, J.; Coleman, S.; Stumpel, J. E.; Ben Azouz, A.; Diamond, D.; Schenning, A.; Molecular, P. H. J. Design of LightResponsive Hydrogels, for in Situ Generation of Fast and Reversible Valves for Microfluidic Applications. Chem. Mater. 2015, 27, 59255931. 